6.

\title{
Zur Geschichte der Mastdarmverschliessung.
}

\author{
(Eine Berichtigung.)
}

Von A. v. Sehleiss, königl. Leibarzt.

Hr. Dr. Hermann Friedberg erwähnt in einem Artikel "Ueber einen Fall von angeborener Aftersperre" (Virchow's Archiv 1859. Bd. 17. V. S. 150) eines in der Zeitschrift für rationelle Medicin von Henle und Pfeufer. N. F. Bd. III. S. 366 unter dem 'Titel ,Glückliche Heilung einer Atresia recti ex retroversione vesicae urinariae congenita" von mir mitgetheilten Falles mit folgenden Worten: „Der Knabe, bei welchem Hr. v. Schleiss den Mastdarm durch Stich eröffinete, war zwar zu der Zeit, als seine Krankheitsgeschichte veröffentlicht wurde, 25 Monate alt, Jitt aber öfter an gefahrdrohender Schwierigkeit den Stuhl zu entleeren, weil der künstliche Kanal sich verengerte." - Ich kann niclit umbin, mir die Freileit zil nchmen, diese Aeusserung dahin zu berichtigen, 1) „dass die einige Zeit lang eingetretene Schwierigkeit, den Stuhl zu entleeren, in keiner Hinsicht gefahrdrohend gewesen war, und 2) dass dieselbe keineswegs von einer Verengerung des künstlich angelegten Kanales verursacht worden. Von dem Zeitpunkte an, als ich das methodische Wechseln der in den künstlichen Kanal eingelegten elastischen Röhren unterliess, ist eine Wiederverengerung des Kanales $\mathrm{nicb}$ t eingetreten, in Gegentheil derselbe hat sich mit dem Waclssthume des Knaben erweitert. Die erwähnte Schwierigkeit, den Stuhl zu entleeren, bestand darin, dass, soviel aus den der Stuhlentleerung vorausgehenden Geberden des linaben zu entnehmen war, ein doppelter Drang zum Stuhle der wirklichen Kothentlecrung vorausging, einmal wenn der Koth aus dem durch die Operation von unten geöffneten unteren Dickdarmende in den künstlich geschaffenen Verbindungskanal eintrat, und ein zweiter, ehe der Koth aus dem Mastdarm durch den After entleert wurde. Dieser Doppelstuhldrang hörte aber allmalig auf, und zwar, wie ich vermuthete, dadurch, dass die Längenmuskelfasern des Dickdarmes mit den Muskeln des Mastdarmes in Berührung und Vereinigung gelangten, indem sich die Wundränder des Dickdarmes wälırend der Vernarbung des Stichkanales den Wundrändern des Mastdarmes allmälig nähterten, - ein Vorgang, wie er sich bei jeder anderen Haut - oder Muskelwunde auch beobachten lässt. Nach meiner Ansicht kann der von mir mitgetheilte Fall nicht mit dem Namen Aftersperre (Atresia ani) belegt werden, - denn es war der After niclt verschlossen und der Mastdarm war vollständig ausgebildet vorhanden, nur dass dieser nach oben, sowie der Dickdarm nach unten blindsackig endigte, und zwischen jenem und diesem die Harnblase gelegen war. Ich hatte ihn daher Atresia recti benannt. In solchen Fällen ist aber die Proctoplastik unausführbar, es müsste denn das Heiligenbein 
resecirt werden. Ich glaube, dass in solchen Fällen allein nur die Operation mittels Troicart und zwar in der von mir angegebenen Weise und mit derselben Nachbehandlung einen günstigen und zweckerfüllenden Erfolg haben wird, ... und dass, wenn sie missglückt oder nicht ausfïhrbar sein sollte, an ihre Stelle nur die Anlegung eines künstlichen Afters per enterotomiam treten könne. Bei Verschliessung des Afters aber, einer wirklichen Atresia ani, - hierin stimme ich mit den Ansichten des Hrn. Dr. Friedberg vollkommen überein, erachte ich die Proctoplastik als die vorzüglichste und empfehlenswertheste Operationsart.

München, im November 1859.

\section{XII.}

\section{Auszuge und Besprecliungen.}

1.

Georg Schmitz, Ueber das Wachsen der Muskeln. (De incremento musculorum observationes physiologicae. Diss. inaug. Greifswald 1858.)

Verf. constatirte mittelst des Budge'schen Reagens (chlors. Kali nad Salpetersäure) :

1) dass durch schlechte Ernährung oder durch gehinderte Functionirung eines Muskels die Zahl seiner Primitivbündel nicht erheblich vermindert wird;

2) dass das physiologische Wachsthum der Muskeln mittelst Anbildung neuer Primitivbündel geschieht.

Zu den Untersuchungen benutzte er die Gastrocnemii von Fröschen. Zwei rom Scheitel bis Anus 36 Lin. lange Thiere wurden ausgesucht; die Wadenmuskeln des einen präparirt, 24 Stunden in das Reugens gelegt und dann gezähit, die Zahl der Bündel betrug 4128. Der andere Frosch wurde 3 Monate lang in einem Glas Wasser aufbewahrt, ohne dass er die entsprechende Nahrung erhielt. Die Zabl der Bündel betrug 4018. Die Länge der Muskeln war beim ersten Frosch 10 Lin., heim zweiten 9 Lin., die Dicke beim ersten $2 \frac{1}{2}$ Lin., beim zweiten 2 Lin.

Darauf zählte Verf. die Bündel der $4 \mathrm{Lin}$. langen, $1 \frac{1}{2}$ Lin. dicken Gastrocnemii eines sebr jungen 18 Lin. Jangen Frosches. Es waren nur 2158.

An einem 39 Lin. langen Frosch wurde ein N. ischiad. durchschnitten. Nach einem Monat starb er, die Muskeln waren $10 \frac{1}{4}$ Lin. lang, auf der gesunden Seite $2 \frac{1}{9}$ Lin., auf der anderen $1 \frac{7}{8}$ Lin. dick. Die Zahl der Bündel war 4218 auf der gesunden, 3918 auf der kranken Seite. 